\title{
EFFECT OF Sc. 11800 (ETHYNODIOL DIACETATE) ON THE GENITAL TRACT OF WOMEN
}

\author{
SHANTI SHAHANI AND ALKA CHIKLIKAR \\ The Department of Endocrinology, T. N. Medical College, and \\ B. Y. L. Nair Charitable Hospital, Dr A. L. Nair Road, Bombay
}

(Received 28th February 1966, revised 29th April 1966)

\begin{abstract}
Summary. Ethynodiol diacetate (Sc. 11800) was given in various dosages from the 5 th day of a cycle for 20 days $(2,1$ and $0.5 \mathrm{mg}$, in combination with $0.1 \mathrm{mg}$ mestranol) to a group of normally menstruating women.

The histological changes in the endometrium on different days of therapy are compared at the different dose levels. Changes in vaginal cytology and cervical mucus during the therapy cycle with different dosages of this drug are discussed.

It is suggested that the low dosage progestin-oestrogen combination may prove a better and a cheaper oral contraceptive.
\end{abstract}

\section{INTRODUCTION}

It is now generally felt that oestrogen-progestin combinations alter the uterine physiology in a manner which is not consistent with normal nidation. The purpose of this communication is to evaluate the effects of varying dosages of Sc. 11800 (ethynodiol diacetate supplied by courtesy of G. D. Searle \& Co. Ltd, England) with a constant amount $(0.1 \mathrm{mg})$ of mestranol on the genital tract.

\section{MATERIALS AND METHODS}

A total of seventy-two patients was investigated for 108 menstrual cycles. The ages varied from 19 to 36 years. The drugs were administered either for contraception or in cases of sterility. Patients were selected from those attending the Endocrinology Clinic of the B. Y. L. Nair Charitable Hospital, Bombay.

All subjects were submitted to the same schedule of drug administration, i.e. from Day 5 to Day 24 of a cycle. Endometrial biopsies and vaginal smears were taken during the 1st, 2nd and 3rd weeks of therapy, preferably in the same cycle.

The dosages of Sc. 11800 employed in this study were $2,1,0.5$ and $0 \cdot 1$ mg. 


\section{RESULTS}

\section{Endometrial changes}

Group I. Sc. $118002 \mathrm{mg}$ plus $0 \cdot 1 \mathrm{mg}$ mestranol. The compound was given to thirty-one patients for sixty-five cycles. Subnuclear vacuolation in the endometrial glands, the earliest sign of secretory activity, appeared by Days 6 to 7 of the cycle ( 2 to 3 days of medication) and became well marked by Day 8 . The appearance of supranuclear vacuoles occurred around Day 11 and could be seen till Day 14 to 15 . Secretion in the lumen of some glands was noted between Day 9 and Day 13. Minimal mitotic activity was seen in some glands but only up to Day 8 . Some stromal oedema became more pronounced after Day 14. The stromal cells exhibited a moderate increase in cytoplasmic volume by Day 12, which increased progressively towards the end of cycle, but pseudodecidual reaction was noted only around Day 23. Also seen in the biopsies towards the end of therapy were increased vascularity and dilated sinusoids. In contrast to the stroma, the glandular development was diminished beyond Day 14 of therapy cycle. The glands became fewer in number and diminished in size, the epithelium changing from columnar during the early days to low columnar and cuboidal in the later stages.

Thus towards the end of cyclic therapy there is marked glandular regression in a well developed stroma (Roland, Glyman, Decker \& Ober, 1964).

Group II: Sc. $118001 \mathrm{mg}$ plus $0 \cdot 1 \mathrm{mg}$ mestranol. This drug was given to eight patients. There was hardly any difference in the sequence of morphological transformation of the endometrium as compared with Group I. Early secretory activity in the glands manifested by intra-epithelial vacuolation became evident within $48 \mathrm{hr}$ of therapy, but failed to progress any further and actually showed changes of regression and progressive atrophy from Day 14 onwards (after 10 days of medication). The stroma developed progressively and showed vascularity and pseudodecidual reaction towards the end of the cycle.

Group III: Sc. 11800 0.5 mg plus 0.1 mg mestranol. This combination was given to sixteen patients for twenty-three cycles. The biopsy material taken on Days 7 to 8 (after 3 to 4 days of therapy) showed minimal tortuosity and the beginning of subnuclear vacuoles which were very clearly defined by Day 8 and persisted till Day 12. However, at places, evidence of slight mitotic activity in the glandular epithelium was present on Day 7. Supranuclear vacuoles with some glandular tortuosity was evident on Day 14 to 15 . Thereafter glandular regression and atrophy became progressively evident though the regression was less severe than with the $2 \mathrm{mg}$ dosage.

Well-marked stromal oedema and vacuolated stromal cells were observed from Day 9 to 10 (by 5 to 6 days of therapy) and progressed to pseudodecidual reaction towards the end of therapy.

Group IV : Sc. 11800 0.1 $\mathrm{mg}$ plus 0.1 mg mestranol. This combination of Sc. 11800 was given to seventeen patients for twenty cycles only, due to limited supplies of the drug.

The sequence of events in the endometrial histology seemed to be different from the previous groups.

The glands showed proliferative changes, as manifested by mitotic activity 


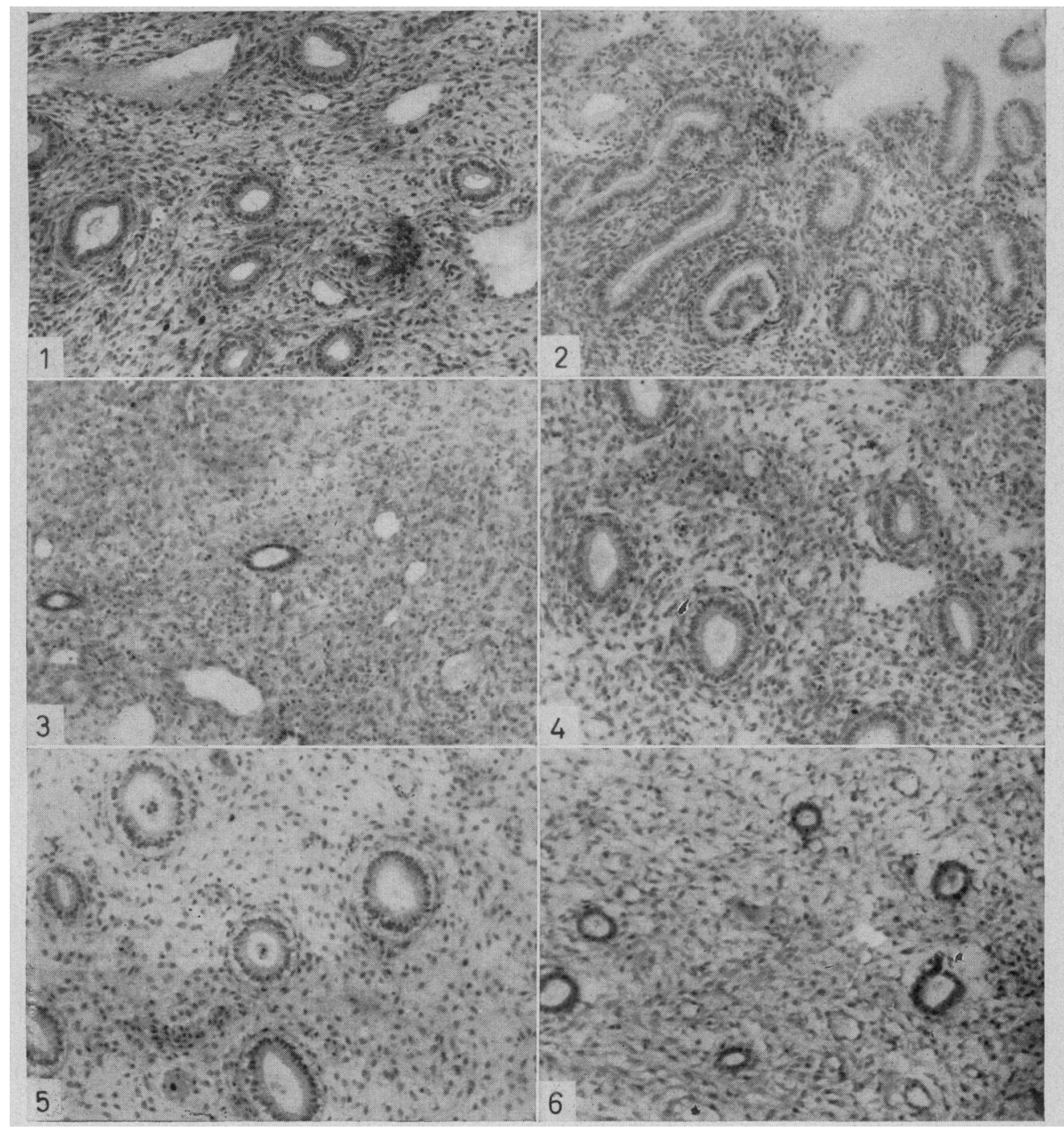

lig. 1. Sc. $118002 \mathrm{mg}$. Endometrial biopsy, on Day 6 (after 2 days of therapy) shows appearance of subnuclear vacuoles and an inert stroma.

FiG. 2. Sc. $118002 \mathrm{mg}$. Endometrial biopsy on Day 11 (after 7 days of therapy) showing subnuclear and supranuclear vacuoles. Slight tortuosity of some glands seen.

Fig. 3. Sc. $118002 \mathrm{mg}$. Endometrial biopsy on Day 23 (after 19 days of therapy). Glandular atrophy, dilated sinusoids and pseudodecidual reaction of stroma seen.

Fig. 4. Sc. $118001 \mathrm{mg}$. Endometrial biopsy on Day 8 (after 4 days of therapy). Subnuclear vacuoles and stromal oedema seen.

Fig. 5. Sc. $118000 \cdot 5 \mathrm{mg}$. Endometrial biopsy on Day 12 (after 8 days of therapy) showing subnuclear and supranuclear vacuoles. Stromal oedema was patchy.

FIG. 6. Sc. $118000.5 \mathrm{mg}$. Endometrial biopsy on Day 23 (after 19 days of therapy). Glandular regression and stromal oedema seen.

(Facing p. 2) 


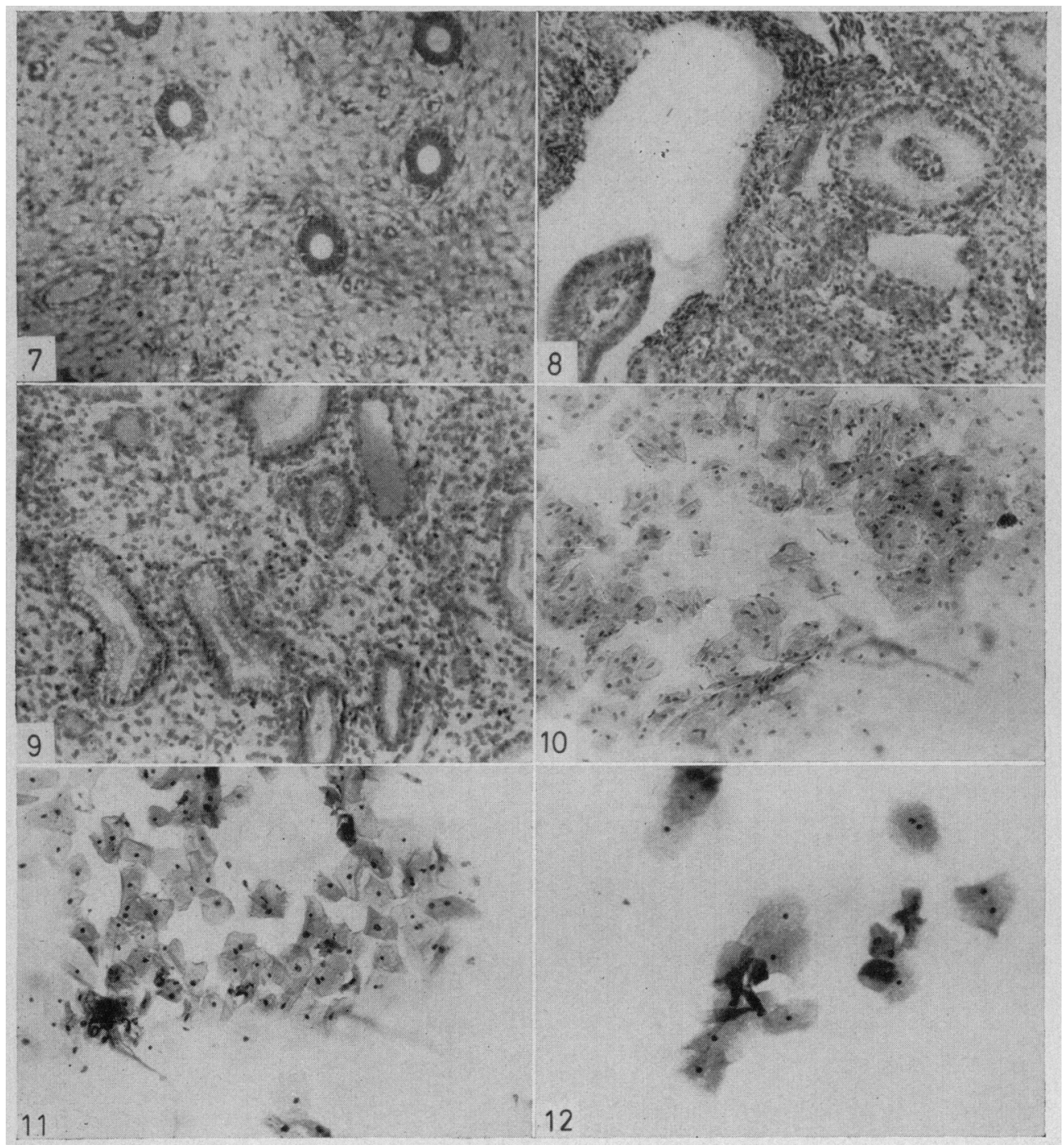

FIG. 7. Sc. $118000.1 \mathrm{mg}$. Endometrial biopsy on Day 7 (after 3 days of therapy. Absence of subnuclear vacuoles. Stroma inactive.

FIG. 8. Sc. $118000 \cdot 1 \mathrm{mg}$. Endometrial biopsy on Day 18 (after 14 days of therapy). Glands show subnuclear vacuoles. No change in stroma.

Fig. 9. Sc. $118000 \cdot 1 \mathrm{mg}$. Endometrial biopsy on Day 21 (after 17 days of therapy). Glands show supranuclear vacuoles and patchy stromal oedema.

FIg. 10. Sc. $118001 \mathrm{mg}$. Vaginal smear on Day 13 (after 9 days of therapy). Slight regression changes seen but not typical of a normal secretory phase.

Fig. 11. Sc. $118000.5 \mathrm{mg}$. Vaginal smear on Day 8 (after 4 days of therapy). Grouping of cells seen but cornification of nuclei still present.

FIG. 12. Sc. 11800 0.1 mg. Vaginal smear on Day 18 (after 14 days of therapy). Grouping of cells seen but cornification of nuclei still present. 
of the glandular epithelium, and pseudostratification, from Day 7 to Day 15 of the treated cycle. Evidence of secretory activity was manifested by the presence of intra-epithelial vacuolation and glandular tortuosity on Days 18 to 21 (after 14 to 17 days of medication). Thereafter regression set in, but it was not as severe as that observed with the previous compounds. The biopsy on Day 24 showed minimal tortuosity of glands and some telescoping. The stroma during the early part of therapy was dense and gradually showed vacuolation of stromal cells by Day 15 which further progressed at places to show slight pseudodecidual reaction, towards Day 22 to 24 . Stromal oedema increased towards the latter part of therapy.

\section{Changes in vaginal cytology}

Vaginal smears taken on different days of treatment with the various combinations failed to exhibit typical progestational changes at any time (Moyer, Tyler, Olsen \& Zeildis, 1964).

There was a moderate regression of the vaginal epithelial cells within the first week of therapy; this occurred with 2,1 and $0.5 \mathrm{mg}$ of Sc. 11800 and persisted with minor variations throughout the cycle. With the $0.1 \mathrm{mg}$ dose, there was mild regression of vaginal cells which even during the last week of therapy exhibited moderate cornification. In some smears marked clumping of cells was evident.

Similar findings were exhibited by the Spinnbarkeit reaction in cervical mucus. With 2, 1 and $0.5 \mathrm{mg}$ of Sc. 11800 , the Spinnbarkeit was maintained during the first 2 weeks of the therapy cycle, but it became negative during the last week. With $0.1 \mathrm{mg}$ Sc. 11800 , the Spinnbarkeit reaction of cervical mucus was maintained throughout the treatment cycle.

\section{DISCUSSION}

It will be noted that with slight variations the sequence of changes in the endometrial pattern produced with 2,1 and $0.5 \mathrm{mg}$ of ethynodiol diacetate plus mestranol is similar, i.e. there is a hastening of the glandular development in the early days of treatment followed by regression of these elements along with pseudodecidualization of the stroma during the latter part of the cycle (Roland, 1958; Marqueo, Perez Vega, Goldzeiher, Martinez-Manautou \& Rudel, 1963; Durkin, Lin \& Kim, 1965). In the case of Sc. $118000 \cdot 1 \mathrm{mg}$ plus mestranol, the endometrium continued to show proliferative changes half way through the cycle and secretory activity in the second half of the cycle appeared similar to changes occurring in a normal cycle. The stroma showed variable amounts of oedema and the pseudodecidual reaction was never marked.

Thus, it may be suggested that this low dosage progestin combination is less likely to produce the atrophic endometria and scanty menses which have been commented upon in cases of prolonged use of these drugs as oral contraceptives. The cost of the drug ought to be reduced because of the low progestin dosage. However, its comparative efficacy as an effective contraceptive needs to be evaluated on a larger scale.

We must be cautious in generalizing from the limited number of cases 
studied in our series, but nevertheless the effects were quite constant in the samples available.

\section{ACKNOWLEDGMENTS}

The authors wish to thank Dr T. H. Rindani, Dean of the T. N. Medical College, for his constant help and encouragement in the study projects of the Endocrine Unit.

The photographs used to illustrate this paper were taken by Dr (Professor) E. D'Souza of the T. N. Medical College and the authors feel indebted to him for the same. Technical assistance of Miss P. V. Dandekar in the preparation of slides is acknowledged.

This study was partly aided by the Ford Foundation Grant for Reproductive Biology in the Endocrinology Unit of T. N. Medical College, Bombay.

\section{REFERENCES}

Durkin, J. W., JR, Lin, T. J. \& KIM Y.J. (1965) Endometrial effects produced by the oral administration of steroids to control the reproductive cycle. Am. F. Obstet. Gynec. 91, 110.

Maqueo, M., Perez Vega, E., Goldzieher, J., Martinez-Manautou, J. \& Rudel, H. W. (1963) A comparison of the endometrial activity of three synthetic progestins used in fertility control. Am. F. Obstet. Gynec. 85, 427.

Moyer, D., Tyler, E. T., Olsen, H. J. \& Zeildis, L. J. (1964) Vaginal cytohormonal effects of long term cyclic administration of synthetic progestin. Fert. Steril. 15, 164.

Roland, M. (1958) Effects of norethynodrel on human endometrium. Ann. N.Y. Acad. Sci. 71, 638.

Roland, M., Glyman, M. J., Decker, A. \& Ober, W. B. (1964) Classification of endometrial response to synthetic progestogen estrogen compounds. Fert. Steril. 15, 143. 